\title{
Biografías
}

\section{Marie Curie. La senda del personaje en busca de su enfermedad}

\author{
Carmen Burgaleta Alonso de Ozalla \\ Dra. en Medicina. Especialista en Hematología Hemoterapia. Catedrático Emérito Departamento de \\ Medicina Universidad de Alcalá; carmenburgaleta1@ gmail.com; https://orcid.org/0000-0002-1272-8213 \\ DOI: https://doi.org/10.37536/RIECS.2020.5.1.199
}

Recibido: 27/03/2020; Aceptado: 18/04/2020; Publicado: 30/05/2020

Resumen: Marja Sklodowska, mundialmente conocida como Marie Curie, sufre desde la infancia reveses y privaciones que influyen en su personalidad, capacidad de trabajo y superación. La ocupación rusa en Polonia, el fallecimiento de su madre y hermana mayor; necesidad de trabajar desde la adolescencia. Con 23 años emigra a Francia, para reiniciar los estudios licenciándose en Física y Matemáticas. Casa con otro científico, Pierre Curie, con la determinación de dedicar su vida a la investigación. Elige estudiar las radiaciones a partir de la uranita. Descubre el polonio y el radio. Recibe 2 premios Nobel. Queda viuda con 2 hijas, se repone y es profesora de La Sorbona, crea el instituto del radio y en la guerra crea un servicio móvil con aparatos de rayos $\mathrm{X}$ para atender soldados heridos. Tras la guerra inicia la búsqueda de recursos para promover la investigación. Fue generosa e independiente, manteniéndose al margen de movimientos populistas, rompiendo con cualquier limitación de la época. A partir de 1920 se conocen los peligros del radio, las lesiones que produce en los tejidos y el fallecimiento por cáncer o leucemia en personas expuestas a radiaciones. Marie Curie sufre quemaduras, cataratas, lesiones en tracto urinario y anemia. Fallece a consecuencia de las radiaciones recibidas a lo largo de su vida que afectan a las células hematopoyéticas. El diagnostico final ha recibido distintas valoraciones, siendo lo más probable que presentase una aplasia medular o una leucemia oligoblástica, como evolución de un síndrome mielodisplásico secundarios a las radiaciones.

Palabras Clave: Marie Curie, Radio, Polonio, Premio Nobel, Radiación, Aplasia, Leucemia aguda, Anemia, Síndrome Mielodisplasico.

\begin{abstract}
Marja Sklodowska, known as Marie Curie, suffers setbacks and deprivations from chilhod that influence her personality, determination and resistence. Repression in subdued Poland, the death of his mother and older sister; work from adolescence for economic reasons. He emigrated to Paris at the age of 23, and graduated in Physics and Mathematics with honors. She married another cientist, Pierre Curie, with the determination to dedicate his life to research. Choose to study radiation from uranite. Discover polonium and radius. Receive 2 Nobel awards. She became widow with 2 daughters. But recovered and becamen Profesor at Sorbonne University and and creates The radio Institute. During war, she contributes to help wounded soldiers, by using the $\mathrm{X}$ Rays. After war Marie is involved to obtain resources for research. She was generous and independent, staying out of populist movements. The dangers of radium, the injuries that it produces in the tissues and the death from cancer or leukemia in people exposed to radiation have been known since 1920 . Marie Curie suffers burns in hands, cataracts, urinary tract injuries, and anemia. She dies as a consequence of the radiation received throughout its life that affects the hematopoietic cells. The final diagnosis has received different evaluations, the most probable today is bone marrow aplasia or oligoblastic leukemia, as an evolution of a myelodysplastic síndrome, secondary to radiation.
\end{abstract}

Key words: Marie Curie, Radium, Polonium, Nobel Prix, Radiatión, Aplastic Anemia, Acute Leuckemia, Anemia, Myelodisplastic Syndrome. 


\section{Introducción}

La vida de Marja Salomé Sklodowska, conocida universalmente como Marie Curie continúa siendo objeto de estudio y reflexión casi 100 años después de su muerte. Su extraordinaria relevancia científica es mundialmente conocida, tanto por sus aportaciones a la ciencia, como por los hitos logrados a lo largo de su vida y posteriormente; todo lo cual aumenta en importancia al conocer la época y circunstancias en que vivió y que llevan a interesarse por la persona, sus cualidades humanas y pasiones, con independencia de sus excepcionales dotes intelectuales. Existen numerosas biografías, siendo la realizada por su hija menor, Eva, la que mejor describe las circunstancias en las que tuvo que vivir, el entorno familiar, su determinación, capacidad de sacrificio, generosidad y personalidad, pero es sin duda a través de las notas autobiográficas de Marie Curie y su diario donde descubrimos su sensibilidad, capacidad de amar, de sobreponerse al dolor y su fuerza para evolucionar. Lo que la llevo de representar los ideales de la ciencia pura a la participación en una campaña mediática para conseguir fondos y crear un legado que favoreciera la investigación de generaciones futuras. Siempre se mantuvo independiente, sin participar en el movimiento social comunista ni en el movimiento feminista, que han querido utilizarla reiteradamente.

Marie Curie Sklodowska representa un ejemplo y estimulo único en una sociedad cada vez más insensible al compromiso, el esfuerzo y la fidelidad a unos ideales. Contribuyó a crear un área nueva de tratamiento y múltiples aplicaciones en medicina, falleciendo como consecuencia de la radioactividad recibida, aunque no disponemos de un diagnostico unánime sobre la enfermedad de la que falleció y difiere según la fuente consultada: Anemia perniciosa, Aplasia medular, Anemia perniciosa aplásica grave y leucemia aguda, algo que merece ser discutido a la luz de los conceptos actuales.

\section{Resumen Biográfico y hechos relevantes}

Nace en Varsovia (Polonia) el 7 de noviembre de 1867, quinta hija de una familia culta, su padre era profesor de física y matemáticas y la madre profesora de música. Polonia estaba sometida a Rusia que imponía el estudio de la lengua rusa y prohibía el acceso a la Universidad a las mujeres y que rebajó la situación económica de la familia. Estudió junto a sus hermanos en instituciones clandestinas polacas y con ayuda de su padre; matriculándose al final oficialmente en la educación pública, obteniendo Medalla de oro. Su hermana mayor muere en 1876 de tifus y su madre dos años más tarde, de tuberculosis. Sufre una importante depresión, y ante la imposibilidad de completar su formación, se emplea dado clases particulares. A los 18 años decide alejarse de Varsovia y se emplea de institutriz en Szazuki, para ayudar económicamente a su padre y con la ilusión de ahorrar para ir a Paris, donde su hermano mayor Josef estudiaba medicina, a completar sus estudios. Lee todo lo que puede y establece relación con el hijo mayor de la familia Zurowsky, Casimir, joven inteligente con el que compartía lectura y aficiones. Este primer amor fue cortado de raíz por los padres de Casimir, que aspiraban a un mejor partido; sufre un nuevo rechazo y humillación, aunque sigue trabajando en la casa, dedicando las horas libres a estudiar y a dar clases gratuitamente a niños polacos de la localidad que carecían de medios; esta situación se prolongó más de lo previsto para ayudar a que su hermana Bronia fuese a Paris, antes que ella. Por fin en 1889, con 22 años regresa a Varsovia, donde vuelve a dar clases particulares. Allí contacta con jóvenes científicos a través de la Universidad volante, entusiasmándose por la experimentación. En 1891, por fin puede ir a Paris, animada por Bronia; llega a tiempo de comenzar el curso Académico y se matricula en la licenciatura de Física. Los sufrimientos pasados han fortalecido su carácter, determinación y ganas de independencia, por lo que pronto deja la casa de su hermana, casada y con un niño, alojándose en una buhardilla sin calefacción del barrio latino, donde vive en condiciones extremas, dedicada por entero al estudio de las materias y mejorando el nivel de francés. Dos años más tarde consigue la licenciatura en física, siendo la primera de su promoción. Ello la proporciona la Beca Alexandrovich (para polacos destacados, que estudian fuera del país) y tras unas vacaciones en Varsovia, se matricula en matemáticas, graduándose al año siguiente con el $2^{\circ}$ puesto.

En 1894 conoce a Pierre Curie, a través de un compañero polaco, Pierre era un físico apasionado por el estudio y la investigación de la simetría de los cristales y los campos magnéticos, que se sintió 
inmediatamente atraído por ella invitándola a la lectura de su tesis y evita que Marie regrese al terminar sus estudios universitarios a Polonia, para quedarse. Ambos reconocen tener valores coincidentes, en su amor por la ciencia pura y la investigación, pudiendo prescindir de bienes materiales, distinciones académicas e innecesarios actos sociales. A su vez aman el campo y el deporte. Se casaron en julio de 1895 mediante una sencilla ceremonia civil; Marie encargó un sencillo vestido negro con el que poder trabajar en el laboratorio posteriormente; fascinados por un invento reciente, la bicicleta, compraron un par de ellas con los regalos de boda; con ellas realizaron su viaje de novios y posteriores vacaciones. Marie, adquiere el apellido de su marido y asume su compromiso de crear una familia, tiene 28 años, mayor para la época, hace 10 que inició su trabajo como institutriz y su determinación por hacer una carrera científica es más fuerte cada día. Elige investigar las propiedades de la uranita, recientemente descritas por Becquerel, observando la energía desprendida por el uranio y convence a Pierre para que cambie su foco de interés. Empiezan a aislar Uranita de la pecblenda, una forma de carbón, en un cobertizo prestado, sin medios económicos, cargando personalmente los sacos de carbón. En 1887, nace su primera hija Irene, conllevando un trabajo agotador físicamente con las tareas de una mujer casada. Tiene un segundo embarazo, estando enferma durante ese año lo que la obliga a parar e ir al campo a descansar, pero tiene un parto prematuro y la niña fallece a las 24 horas. El resto es conocido aíslan un nuevo elemento más potente que el uranio al que Marie da el nombre de polonio, en recuerdo de su amada Polonia y que pronto es superado por un nuevo elemento mucho más potente al que por las radiaciones que emite, una luz azulada y brillante, llaman radio.

En 1903 los esposos Curie reciben el premio Nobel de Física, junto a Becquerel por descubrir la radioactividad. Marie es la primera mujer en recibir un Nobel, aunque el discurso lo hace Pierre, que no escatima referencias de reconocimiento al papel de Marie. Ambos decidieron rechazar los derechos de patente sobre el radio, ofreciendo su descubrimiento a la ciencia y proporcionaron desinteresadamente radio, así como el costoso método de aislamiento que habían llevado a cabo para obtenerlo y purificarlo, a otros investigadores. Ya habíamos dicho que creían en la investigación pura. Gracias al dinero del premio Nobel mejoran su situación y las condiciones de investigación. En 1904 Marie lee la tesis Doctoral y nace su hija Eva, cuidan las niñas con ayuda de familiares, sin abandonar su trabajo. Pierre es nombrado Profesor de la Sorbona y Marie jefe de laboratorio, dan clases y continúan trabajando incansablemente, aunque Pierre padece de dolores articulares, quemaduras en dedos y otras dolencias. El 9 de abril de 1906, al día siguiente de regresar a Paris de unas vacaciones en el campo, fallece Pierre atropellado por un coche de caballos, sumiéndose Marie en la mayor desolación imaginable. Viuda y con dos niñas pequeñas, sin su compañero de ideales, de trabajo y de vida, al que amaba profundamente. Parece imposible que tras este nuevo golpe del destino se sobrepusiera, ni que pudiera recogerlo en su diario, describiendo sus sentimientos, recuerdos y emociones desde el día de su muerte: "Querido Pierre, a quien no volveré a ver" (1906-1907). Este diario nos muestra a una mujer dulce, enamorada, apasionada, que ama la naturaleza, las flores y disfruta viendo crecer a sus hijas, una imagen que no coincide con la imagen sombría y seria de la mayoría de las fotos y descripciones.

Tras morir Pierre, Marie es la primera mujer nombrada Profesora de la Sorbona, ocupando la Catedra de su marido. Escribe un tratado sobre la radiactividad y reinicia su trabajo. Cinco años después sufre una campaña de persecución y acoso mediático por la prensa, debida a su relación con Langevin, brillante investigador, antiguo amigo y compañero de los Curie. Estamos en 1911 y Marie es rechazada por la Academia debido a la campaña sufrida. Ello no impide que ese mismo año, recibe el segundo premio Nobel, por descubrir el Polonio y el Radio; esta vez el Nobel de Química en solitario, que tarda en recoger debido al agotamiento por la presión sufrida

Estos periodos de descanso se siguen de una renovada energía para emprender nuevos proyectos. El radio empieza a estar de moda y Marie crea el Instituto del radio (hoy fundación Curie), para proseguir los estudios en 1912. El edifico se termina en 1914 y tiene que cerrar por estallar la $1^{a}$ Guerra Mundial. Durante la Guerra Marie busca una forma de servir a su patria adoptiva, con apoyo de la Cruz Roja crea un Servicio de Unidades móviles, para realizar radiografías a los heridos en el frente, este hecho de heroísmo y patriotismo, manifiesta de nuevo la capacidad de resolución, 
organización y sacrificio de esta mujer extraordinaria. Consiguió reclutar aparatos de rayos $\mathrm{X}$ y furgonetas. Para ello aprendió a conducir, a utilizar los equipos y a realizar Radiografías, instruyendo en primer lugar a su hija Irene y a continuación a un grupo de mujeres, dado que los hombres estaban en el frente. Estas unidades conocidas como las "Petit Maries" realizaron más de 500.000 radiografías, con indudables beneficios. Además, consiguió salvar el radio puro del laboratorio, trasportándolo personalmente al banco Nacional. Al terminar la guerra Marie se convirtió en una heroína para los franceses, pero los tiempos habían cambiado y había que reemprender el trabajo en el instituto del radio, aunque las ayudas económicas no llegaban y Marie aceptó ir a EEUU con sus hijas para recaudar fondos. El viaje fue organizado por la periodista y editora americana Marie Mattingley Meloney (Missi), que llevó a cabo una campaña de gran propaganda mediática. El viaje fue un éxito, logrando dinero y 1 gr de radio puro, adquirido con donaciones de mujeres americanas (este elemento estaba de moda y había alcanzado un enorme precio). Marie, se convierte en la mujer más influyente de Francia y la requieren los compromisos y conferencias por toda Europa y América, los viajes la fatigan y los actos sociales la siguen disgustando. Mantiene a lo largo de su vida la relación con su familia y pone un especial empeño en la educación de sus hijas, para que no careciesen de los medios y oportunidades de los que ella careció de joven. Esto también dio sus frutos. Su hija Irene siguió la tradición familiar casándose con Frederic Juliot, otro brillante investigador, ambos trabajan en el instituto y descubren la radiación artificial, por lo que reciben el premio Nobel de física en 1935, Irene falleció en 1956 de leucemia aguda. Eva por su parte se licenció en letras y filosofía, siendo concertista, posteriormente escritora y periodista, vivió hasta los 102 años. Ambas tuvieron una posición de gran influencia a lo largo de su vida.

Marie Curie sigue acudiendo al laboratorio, hasta poco antes de su fallecimiento en 1934, sin querer reconocer abiertamente la causa de sus dolencias. Fue enterrada, con toda sencillez, junto a su marido en Sceaux. En 1995, siendo presidente de Francia Francois Miterrand, los restos de Pierre y Marie Curie, fueron trasladados al Panteón de Paris.

\section{Efectos de las Radiaciones. La Historia Clínica de Marie Curie}

Tras la guerra, la Curie terapia se puso rápidamente de moda; además de las aplicaciones en el tratamiento de diversos tumores, se realizaron productos con radio para aplicaciones cosméticas, o como reconstituyente, como el Radiothor, (liquido bebible conteniendo radio y mesotorio que originó numerosas víctimas). Paralelamente se comenzaba a saber que el radio no era inocuo y se iban conociendo lesiones y enfermedades tras exposición a él. Antes de 1920, aunque los efectos del radio sobre células normales no se habían investigado, era ya una evidencia que tenía efectos nocivos sobre diversos tejidos en el cuerpo humano. Las primeras consecuencias conocidas fueron las quemaduras en piel, las cataratas, dolores en extremidades y fatiga por trabajar en atmosfera cargada de Radon. El manejo en el laboratorio ocasionaba en manos ampollas, dolores y llagas que permanecían como quemaduras. Pierre y Marie las presentaron y era habitual verla frotándose las manos, para aliviar el escozor.

En 1920 llegó la alarma de varias defunciones en un hospital de Londres entre los que trabajaban con radio. En 1924 Theodore Blom, un dentista de Nueva York, describió la "radium jaw", mandíbula de radio, al observar que 17 mujeres jóvenes que trabajaban en una fábrica pintando esferas luminosas en relojes, presentaban al cabo de años este cáncer, que provocaba su fallecimiento; la pintura contenía radio y mesotorio y la aplicaban con un pincel que chupaban para afinarlo y facilitar la correcta aplicación de la pintura. Durante esos mismo años amigos o antiguos colaboradores, que habían trabajado en el laboratorio con radio fallecieron de cáncer, anemia o leucemia (Loie Fuller, Madame Arnaud, Maurice Demenitroux y Marcel Delamander), así como Mme. Cotello, amiga de Marie que trabajaba en Varsovia con Polonio. El radio se reconocía finalmente como un arma de doble filo que no solo inhibía la proliferación de células neoplásicas, sino que también afectaba a las células sanas, comprometiendo el material genético, disminuyendo las defensas, además puede penetrar en la corriente sanguínea permaneciendo por periodos prolongados y afectar a los progenitores hematopoyéticos de la médula ósea, que es muy radiosensible, lo que explica el desarrollo de anemia y leucemia. Aunque aún no es totalmente conocido como induce daño celular la radioactividad, se 
sabe que genera iones, peróxidos y radicales libres, las grandes moléculas de DNA pueden dañarse en proporción directa a la energía radiante recibida; esta se mide en Greys (1 Grey es la energía absorbida equivalente a 1 joule/ $\mathrm{kg}$ de masa y es igual a100 rads). Los efectos de una exposición aguda a grandes dosis de radioactividad pueden tolerarse peor que la exposición crónica a pequeñas dosis, eso unido a la sensibilidad individual podría explicar la resistencia de Marie Curie a una exposición tan directa y prolongada. De hecho, en 1922 Francia no disponía de un comité de investigación de los efectos de la radiación. En el laboratorio usaban placas de plomo para protegerse y a partir de 1924 se estableció un protocolo específico de protección, probablemente insuficiente y con escaso control, dado que se asumía que era responsabilidad de cada investigador su protección ante las radiaciones. En 1926 Marie escribe por primera vez sobre los peligros del radio.

Una historia clínica y epidemiológica de Marie Curie sobre las patologías sufrida durante los más de 30 años en contacto con elementos radioactivos nos revela las siguientes:

- Quemaduras: Lesiones secundarias a quemaduras en dedos de las extremidades superiores, como hemos visto previamente, precedidas de enrojecimiento picor y ampollas.

- Cataratas: Las presentó a temprana edad, aunque se resistió a reconocer las limitaciones ocasionadas por su pérdida de visión (su ayudante le colocaba los objetos en el laboratorio para que los reconociese por palpación). Fue intervenida en cuatro ocasiones a consecuencia de las cataratas entre 1923 y 1930.

- Anemia. A lo largo de su vida, sufrió episodios de agotamiento, que la obligaban a retirarse al campo, o ingresar en una clínica. La causa de esta "anemia" era de diversa etiología; mientras la presentada en 1897, tras el nacimiento de Irene, era con toda probabilidad una anemia carencial, probablemente ferropénica, secundaria a las demandas de hierro durante la gestación y la lactancia y que se asociaba a la probable depresión post parto en una mujer que se sometía a un trabajo exhaustivo y no se alimentaba bien. En 1902, pasa prácticamente todo el año enferma con síntomas de anemia; estando de nuevo embarazada, sufre un parto prematuro, falleciendo la niña. A partir de 1911 ingresa en una clínica con anemia y fiebre diagnosticándola de "infección crónica de ureter, debido a lesiones previas en área pélvica", en relación con radiaciones o una tuberculosis previa; reingresa ese mismo año con pielonefritis, siendo intervenida quirúrgicamente, todo lo cual justifica que la anemia, en esta ocasión, sería una anemia de trastornos crónicos, asociada a la infección.

Ya vimos su actividad, para la realización de Radiografías, durante los años de la guerra y su implicación en viajes y conferencias por todo el mundo a partir de la exitosa campaña por E.E.U.U. aunque frecuentemente se quejaba de cansancio, limitando en lo posible su asistencia a cenas y actos sociales. Estas afecciones y dolencias, no impidieron que Marie Curie continuase trabajando en proyectos y compromisos internacionales y acudiendo al Laboratorio del Instituto Curie (hoy Fundación Curie), hasta poco antes de caer irremisiblemente enferma. Desde enero de 1934 su cansancio iba en aumento y escribe a su hija Irene: "He redactado una resolución provisional que puede servir de testamento en cuanto al gramo de radio y la he puesto junto a los documentos de América, en un paquete cuyo contenido está en rojo. Todo se encuentra en el cajón del mueble de la sala de estar ...". En mayo había aumentado su astenia. Le diagnosticaron de tuberculosis, siempre el mal de la época, del que falleció su madre, siendo por prescripción médica, a un sanatorio en Sancellemoz (Alta Savoya, Francia), ingresó con fiebre, extenuada y con una palidez extrema. La analítica de sangre demostró un rápido descenso de glóbulos rojos y blancos, mientras que las Radiografías de tórax descartaron tuberculosis. Es diagnosticada, en ese momento de Anemia perniciosa e inicia tratamiento, sin experimentar mejoría, fallece el 4 de julio. 


\section{Diagnostico final: Discrepancias y valoración actual del diagnostico}

¿Qué enfermedad causó la muerte de M. Curie?, ¿desde cuándo estaba enferma? El informe final firmado por el Dr. Tobé en Sancellemoz dice: "Mme. Curie muere en Sancellemoz el 4 de julio de 1934. La enfermedad fue una anemia aplásica perniciosa de rápido desarrollo febril. La medula ósea no reacciona, probablemente porque ha sido dañada por largo acumulo de radiaciones". Esta descripción es la presentada en la extensa biografía escrita por su hija Eva (Madame Curie, una biografía de Marie Curie por Eva Curie), que es la más detallada, y contrasta con el diagnostico de leucemia aguda del resumen biográfico firmado por su nieta Helen Longevin Joliot y Monique Bordry, ex directora del Museo Curie en el libro "Cartas. Marie Curie y sus hijas", del que ambas son editoras. Ambos diagnósticos, junto con el de anemia perniciosa, aparecen alternativamente en biografías, artículos o resúmenes en torno a la figura de Marie Curie, lo cual merece discutirse desde un punto científico actual.

El término anemia Perniciosa, se conoce a partir de la descripción de Thomas Addison en Londres (1855) y Anton Biermer, Zurich (1872) de ahí su nombre inicial "anemia de Addison-Biermer, que se refiere una anemia crónica causada por la falta de secreción de factor intrínseco de Castle por las células parietales del estómago, lo que impide la absorción de la vit B12, aportada con las proteínas de la dieta, identificada en 1948. Ambos son imprescindibles y su falta da lugar a una anemia macrocítica, cuyo origen puede ser por falta de producción de las células parietales por una gastritis crónica, o deberse a una enfermedad autoinmune, con anticuerpos anti factor intrínseco. La enfermedad se popularizó a partir de 1876, debido a una Editorial de amplia difusión en el Lancet. Es evidente que ello no concuerda en la actualidad con la enfermedad que presentó en sus últimos meses Marie Curie, y que su inclusión en el diagnostico final, se debe con toda probabilidad al significado de la palabra perniciosa. En cuanto a la leucemia aguda y la anemia aplasica, o aplasia medular, ambas entidades pueden aparecer al cabo de un tiempo de haber estado expuesto a radiaciones ionizantes, como observaron inicialmente Cour-Brown y Doll, en pacientes irradiados para tratar espondilitis ankilopoyetica. La leucemia aguda, es probablemente la neoplasia más asociada con radiación, en relación con dosis recibida, tiempo de exposición y superficie corporal expuesta. Esta relación ha sido ampliamente estudiada a partir de la segunda guerra mundial, en expuestos a la bomba atómica y posteriormente en Chernóbil. Las radiaciones causan roturas en el ADN, ocasionando delecciones y alteraciones cromosómicas y moleculares que dan lugar a leucemias agudas. La enfermedad ocasiona un trastorno de diferenciación celular, con acumulación de células inmaduras anormales, denominadas blastos y alteración y disminución de otras líneas hematopoyéticas. En sangre periférica la leucemia aguda se manifiesta en la mayoría de los casos y variedades con leucocitosis, presencia de blastos, anemia, asociada frecuentemente con trombopenia. La descripción de la analítica realizada durante los meses de estancia de Marie Curie en Sancellemoz, refiere descenso de glóbulos rojos y blancos; no consta la aparición de células inmaduras no identificables (blastos), ni que presentase trombopenia en ningún momento y desde el punto de vista clínico se describe solo la presentación de fiebre y síntomas generales. Actualmente reconocemos casos de leucemias en pacientes mayores con una medula pobre, en la que destaca stop madurativo y aumento de blastos, que cursa con citopenias periféricas. Esta forma de leucemia aleucémica podría dar una clínica y citología más en sintonía con la citada información clínica, en caso de que no se hubiese realizado y examinado una biopsia de medula ósea por un citólogo o patólogo experto. Carecemos de información al respecto, aunque es lo más probable, teniendo en cuenta que estábamos en 1934 en un sanatorio antituberculosos y que la paciente rechazo ser transfundida, terapia experimental en ese momento, y su hija Eva quiso que se le evitase sufrimiento innecesario. Nos quedaría discutir el informe de aplasia medular de evolución rápida, ello concordaría con la aplasia medular severa o muy severa, aunque sorprende de nuevo la falta de alusión a la cifra de plaquetas, o diátesis hemorrágica. En cuanto al efecto de la radioactividad, la aplasia puede ser consecuencia, no solo de una dosis aguda importante, sino también de una exposición prolongada a radiaciones; de hecho, la exposición a bajas dosis de radiación es menos dañina sobre el estroma celular, que puede tolerar radiación fraccionada con cierto grado de reparación celular. En este caso la descripción de evolución rápida, puede coincidir si se refieren a la evolución observada en los dos meses de ingreso 
en Sancellemoz, pero llevaba varios meses antes de su ingreso con síntomas de anemia. Por otro lado, si nos remontamos a la historia clínica de Marie Curie, es posible que presentase una anemia desde hacía bastantes años, lo que la obligaba a alejarse del laboratorio. En este sentido podríamos pensar hoy en día que padecía una anemia refractaria, encuadrada dentro de los síndromes mielodisplásicos (SMD). Estos trastornos, fueron descritos por primera vez en 1953 por Block. "Los SMD son un grupo heterogéneo de alteraciones clonales de los progenitores hematopoyéticos de la médula ósea, lo que origina una hematopoyesis ineficaz, con displasia en una o más de las líneas celulares, cursando con citopenias periféricas, fundamentalmente anemia. El trastorno es progresivo, pudiendo evolucionar a leucemia aguda hasta el 30\%". Entre sus causas hay que destacar la exposición de forma crónica a radiaciones por exposición laboral, en determinaciones diagnosticas o terapéuticas, aplicadas a otras neoplasias, al igual que en leucemias agudas mieloblásticas. Los SMD cursan con citopenias en sangre periférica con medula ósea normo o hipercelular, en la mayoría de los casos, aunque del 10 al $20 \%$ de los SMD son hipoplasicos. La celularidad medular de los SMD hipoplasicos es inferior al 30\% en menores de 60 años, e inferior al $20 \%$, en los mayores de 60 años, por lo que pueden ser dificilmente diferenciables de una aplasia.

Dada la información disponible sobre la enfermedad y los antecedentes de Marie Curie, cabe la posibilidad de que desarrollara una aplasia medular el último año de su vida que evolucionase en los dos últimos meses, o más probablemente, que llevase tiempo padeciendo un Síndrome mielodisplásico, que cursase inicialmente con anemia moderada, con acentuación de la anemia y leucopenia, al progresar irrevisiblemente el fracaso hemopoyético, dando lugar a las manifestaciones clínicas, presentadas por la paciente en los últimos meses; fiebre importante, probablemente asociada a infección e intensa postración, que obliga a permanecer en cama. El diagnostico de SMD no se ha barajado en la literatura, dado que fueron descritos después de su muerte y de la biografía que publicó su hija Eva, un año más tarde, pero hoy sabemos que la relación entre los SMD, la Aplasia Medular y la Leucemia Aguda es grande y que estos pueden ser la antesala de cualquiera de estas entidades. Por todo lo anterior, podemos aclarar algunos aspectos de la enfermedad final, con arreglo al conocimiento actual de estas entidades y aunque no podemos confirmarlo, sin informe de biopsia de médula, nos inclinamos a pensar, dada la historia clínica e información disponible, que Marie Curie padecía un SMD, que evolucionó finalmente a una aplasia medular o una leucemia oligoblástica, no habiendo duda de que falleció a consecuencia de las enormes cantidades de radio que necesariamente absorbió a lo largo de su vida. Los cuadernos de trabajo y enseres del laboratorio de los esposos Curie se hallan conservados en plomo, debiéndose mantener cerrados durante más de 1000 años por la cantidad de radioactividad que contienen; ello confirma la extraordinaria genética de Marie Curie, que a pesar de ello pudo mantener una vida activa hasta los 67 años al servicio de la humanidad.

Agradecimientos: A la Dra. Rosa Díaz y a José Ramón de Salas por poner a mi disposición las obras y biografías de Marie Curie de sus bibliotecas particulares.

\section{Referencias Bibliográficas}

1. Madame Curie. A biography of Marie Curie by Eve Curie. 2017 ISHI press international. USA. Publicada en 1938. Traducción por Vicent Shean. ISBN: 4-87187-771-X 978-4-87187-771-8

2. Marie Curie. Por Robert Reid. En: Grandes biografías. № 11. Biblioteca Salvat. Ediciones Salvat, na 1984 ISBN:84-345-8145-0

3. Marie Curie. Militante de la ciencia pura. Jose Luis Aranguren. Prologo en: Grandes biografias. Ed. Salvat: 1984: 9 a 11 ISBN:84-345-8145-0

4. Cartas. Marie Curie y sus hijas. Clave Intelectual (Ci) editores. 2015. Titulo original. Marie Curie et ses fills. Lettres Pigmalion 2011 Paris. Ed. Helen Langeven-Joliot y Monique Bordry. ISBN:978-84-943433-7-7

5. Marie Curie. Escritos Biográficos. Editado por El espejo y la Lampara 2011. Universidad Autónoma de Barcelona (UAB). ISBN:978-84-938717-1-0

6. La ridícula idea de no volver a Verte. Rosa Montero. 2013. Seix Barral. 2013. ISBN:978-84-322-2271-9 
7. La radiactividad y los elementos. Marie Curie. El secreto mejor guardado de la Materia. Adela Muñoz Paez. National Geographic. 2015 RBA revistas, SL. ISNN: 1576-8880

8. Marie Curie. Dos veces Nobel. En la cabecera de los protagonistas de la historia. Nestor Lujan. 1992:123125. Ediciones Doyma, S.A.ISBN 84-7592-520-0

9. Warren S, Dunplace. Effects of radiationn on normal tissues. Effects of radiation on the blood and the hemopietic tissues including blood, spleen, thymus and lynphoid nodes. Archives Pathol. Lab Med. 34:562.1942.

10. Cronkite EP. Hematology diagnosis and therapy of radiation therapy of radiation injured. US Armed Forces Med. 56: 1951

11. Neal S. Young. The pathogenesis and pathophysiology of aplastic anmia. in: Hoffman. Chapter 10: 122-160; 1991. Churchil and Livingstone. ESBN 0-443-08643-5

12. Fiedner TH, Norhdurit W, Calvo W. Development of radiation late effects on the bone marrow after single and chronic exposure. Int.J.Radiot. Biol. 49: 35. 1980

13. Biermer A: Uber einer Forn von progresiver perniciöser Anämie. Correspondenzbl Schweitz Arzte 2:15,1872.

14. Editor: Pernicious Anemia: A new disease. Med times and Gazette 2:581,1876.

15. Castle WB: Development of knowledge concerning the gastric intrinsic factor and its relation to pernicious anemia. New England J. of Med.249-603: 1953.

16. Fenwick S: On atrophy of the stomach. Lancet 2: 78, 1870

17. Court-Brown WM and Doll R. Leukemia and aplastic anemia in patients irradiated for ankylosing spondylitis. Medical Research council,Special report series, no. 295. Her Majesty's Stationery office. 1957.

18. B. Lowenberg Ed. In Acute Leukemia and Myelodysplasia. . Balliere's Clinical Haematology vol 9, I: 1996, ISSN 0950-3536.

19. Flora E. Van Leeuwen. Risk of acute myelogenous leukemia and myelodysplasia following cancer treatment. Balliere's Clinical Haematology vol 9, I: 57-85. 1996, ISSN 0950-3536.

(C) 2020 por los autores; Esta obra está sujeta a la licencia de Reconocimiento 4.0

Internacional de Creative Commons. Para ver una copia de esta licencia, visite http://creativecommons.org/licenses/by-nc-nd/4.0/. 